\title{
Erratum to: Population-Based Approaches to the Resource-Constrained and Discrete-Continuous Scheduling
}

Ewa Ratajczak-Ropel and Aleksander Skakovski

Erratum to:

E. Ratajczak-Ropel and A. Skakovski, Population-Based Approaches to the Resource-Constrained and Discrete-Continuous Scheduling, Studies in Systems, Decision and Control 108, DOI 10.1007/978-3-319-62893-6

In the original version of the book, the following corrections have to be incorporated:

In Cover page, book title "Population-Based Approaches to the Resource Constrained and Discrete Continuous Scheduling" has to be changed to read as "Population-Based Approaches to the Resource-Constrained and DiscreteContinuous Scheduling".

In Table of Contents, author names for Part I (Chapters 1-6) and Part II (Chapters 7-12) have to be corrected as "Ewa Ratajczak-Ropel" and "Aleksander Skakovski", respectively.

The erratum book has been updated with the changes.

The updated original online version for this book can be found at DOI 10.1007/978-3-319-62893-6 